\title{
EFEK MODEL PEMBELAJARAN BERBASIS MASALAH TERHADAP HASIL BELAJAR KOGNITIF TINGGI PADA MATERI POKOK SUHU DAN KALOR DI KELAS X SEMESTER II SMA SWASTA AL HIDAYAH MEDAN T.P 2014/2015
}

\author{
Rizki Andriani dan Sahyar \\ Jurusan Fisika FMIPA Universitas Negeri Medan \\ rizkiandriani21@yahoo.com
}

\begin{abstract}
ABSTRAK
Penelitian ini bertujuan untuk menganalisis efek model pembelajaran berbasis masalah terhadap hasil belajar kognitif tinggi siswa pada materi pokok Suhu dan Kalor di kelas X semester II di SMA Swasta Al-Hidayah Medan T.P. 2014/2015. Jenis penelitian ini adalah quasi eksperimen dengan pretest-posttes tcontrol group design, dengan sampel penelitian dua kelas, kelas eksperimen (X-1) dan kelas kontrol (X-2). Instrumen yang digunakan untuk mengetahui hasil belajar siswa adalah tes hasil belajar dalam bentuk essay sebanyak 10 soal yang telah divalidasi oleh validator. Data yang diperoleh antara lain hasil pretest dan postest. Selanjutnya data tersebut dianalisis dengan statistik yang terdiri dari uji normalitas, uji homogenitas dan uji hipotesis. Hasil penelitian menunjukkan bahwa ada efek yang signifikan model pembelajaran berbasis masalah terhadap hasil belajar kognitif tinggi siswa pada materi pokok suhu dan kalor di kelas X SMA Swasta Al-Hidayah Medan T.P 2014/2015.
\end{abstract}

Kata Kunci: Hasil belajar kognititf tinggi, Pembelajaran berbasis masalah, Konvensional.

\begin{abstract}
This research aimed to analyze the effects of problem based learning model for higher cognitive achievement of students in the subject matter of Temperature and Heat in X class II semester SMA Swasta Al-Hidayah Medan distcrit T.P. 2014/2015. This research is a quasi experimental with pretest-posttest control group design, with a sample of two classes, the experimental class $(X-1)$ and a control class $(X-2)$. The instrument used to determine student learning outcomes is the achievement test in the form of essays by 10 questions that have been validated by the validator. Data obtained include the results of the pretest and posttest. Furthermore, the data is analyzed statistically consisting of normality test, homogeneity test and test hypotheses. The results showed that there was a significant effect of problem-based learning model for higher cognitive achievement of students in the subject matter and the heating temperature in class X SMA Swasta Al-Hidayah Medan T.P. 2014/2015.
\end{abstract}

Keywords: Results cognititf higher learning, Problem based learning, conventional. 


\section{PENDAHULUAN}

Pendidikan

merupakan

pendewasaan peserta didik agar dapat mengembangkan bakat, potensi, dan keterampilan yang dimiliki dalam menjalani kehidupan. Oleh karena itu, sudah seharusnya pendidikan didesain guna memberikan pemahaman dan meningkatkan prestasi belajar paserta didik. Kualitas pendidikan di Indonesia masih jauh tertinggal bila dibandingkan dengan negara lain. Rendahnya daya saing sebagai indikator bahwa pendidikan belum mampu menghasilkan sumber daya manusia yang berkualitas. Hal ini dikarenakan sistem pendidikan di Indonesia masih bersifat Teacher Center artinya pendidikan yang masih berorientasi kepada guru dan bukan kepada siswanya. Proses pembelajaran hingga dewasa ini masih memberikan dominasi guru dan tidak memberikan akses bagi anak didik untuk berkembang secara mandiri melalui penemuan dalam proses berpikirnya. Bila sekolah-sekolah dapat dijadikan proses pembudayaan berbagai kemampuan, nilai dan sikap maka mutu pendidikan di Indonesia akan tercapai. Salah satu kecakapan hidup yang perlu dikembangkan melaluipendidikan adalah keterampilan berpikir. Kemampuan berpikir juga sebagai sarana untuk mencapai tujuan pendidikan yaitu agar siswa mampu memecahkan masalah taraf tinggi.

Berdasarkan hasil wawancara yang telah dilakukan dengan guru mata pelajaran Fisika mengatakan hasil belajar siswa pada ulangan harian tergolong rendah yaitu nilai rata-rata 60 sedangkan Kriteria Ketuntasan Minimum (KKM) untuk mata pelajaran Fisikaadalah 75.Dapat dikatakan nilai rata-rata siswa tidak mencapai kriteria ketuntasan minimal yang diharapkan. Hal ini relevan dengan data yang diperoleh dari angket yang diberikan kepada 30 orang siswa. Sebanyak 50\% (15 orang siswa) berpendapat fisika adalah pelajaran yang sulit dipahami dan kurang menarik, 40\% (12 orang siswa) berpendapat fisika biasa-biasa saja, dan hanya $10 \%$ (3 orang siswa) yang berpendapat fisika mudah dan menyenangkan. Faktor yang menyebabkan rendahnya hasil belajar adalah metode dan model pembelajaran fisika kurang bervariasi.

Permasalahan siswa yang merasa sulit dan bosan terhadap pembelajaran yang hanya menekankan pada aktivitas mengingat, memahami, dan mengaplikasikan (low orderof thinking). perlu diupayakan pemecahannya yaitu dengan melakukan tindakan-tindakan yang dapat mengubah suasana pembelajaran yang melibatkan siswa. Aktifnya siswa dalam pembelajaran maka pembelajaran akan lebih bermakna karena siswa secara langsung diajak untuk mengkonstruksi pengetahuan tersebut. Tantangan masa depan menuntut pembelajaran harus lebih mengembangkan keterampilan high order of thinking.

Adapun yang menjadi tujuan dari penelitian ini yaitu untuk menganalisis hasil belajar kognitif tinggi siswa yang dibelajarkan menggunakan model pembelajaran berbasis masalah lebih tinggi daripada pembelajaran konvensional pada materi pokok Suhu dan Kalor Kelas X Semester II SMA Swasta Al Hidayah Medan T.P.2014/2015.

\section{METODE PENELITIAN}

Jenis penelitian ini termasuk penelitian quasi eksperimen (eksperimen semu),

Tabel 1. Two Group Pretes - Posttes Design

\begin{tabular}{|l|c|c|c|}
\hline $\begin{array}{l}\text { Kelompok/ } \\
\text { Kelas }\end{array}$ & Pretes & $\begin{array}{c}\text { Perla } \\
\text { kuan }\end{array}$ & Postes \\
\hline $\begin{array}{l}\text { Kelas } \\
\text { eksperimen }\end{array}$ & $\mathrm{T}_{1}$ & $\mathrm{X}$ & $\mathrm{T}_{2}$ \\
\hline Kelas kontrol & $\mathrm{T}_{1}$ & $\mathrm{Y}$ & $\mathrm{T}_{2}$ \\
\hline
\end{tabular}

Keterangan:

$\mathrm{T}_{1} \quad$ : Tes awal (Pretest)

$\mathrm{T}_{2} \quad$ : Tes akhir (Postest)

X1 : Perlakuan pada 
Penelitian ini dilaksanakan di SMA Swasta Al-Hidayah Medan yang beralamatkan di Jln. Perguruan. Waktu penelitian yaitu pada semester II tahun pelajaran 2014/2015, tepatnya di bulan April-Mei 2015.

Populasi dalam penelitian ini adalah semua siswa-siswi kelas X SMA Swasta Al-Hidayah Medan pada semester genap T.P. 2014/2015, yang terdiri dari 4 kelas. Dengan menggunakan teknik cluster random sampling, diperoleh sampel dari populasi sebanyak 2 kelas. Kelas eksperimen adalah $\mathrm{X}-1$ yang diberi perlakuan menggunakan model pembelajaran berbasis masalah dan sebagai kelas kontrol adalah kelas X-2 yang dibelajarkan mengguanakan pembelajaran konvensional.

Instrumen yang digunakan dalam penelitian ini adalah tes hasil belajar siswa dalam bentuk essaytest yang berjumlah 10 soal. Tes hasil belajar divalidasi terlebih dahulu dengan validasi isi.

\section{HASIL PENELITIAN DAN PEMBAHASAN \\ Hasil Penelitian}

Hasil penelitian menunjukkan bahwa ada efek yang lebih tinggi dari penggunaan model pembelajaran berbasis masalah terhadap hasil belajar kognitif tinggi pada materi pokok suhu dan kalor di kelas X semester II SMA Swasta Al-Hidayah Medan T.P. 2014/2015. Hal ini dapat dilihat dari nilai rata-rata hasil belajar siswa sebelum diberi perlakuan (pretes) dan sesudah diberi perlakuan (postes). Nilai rata-rata pretes kelas eksperimen dan nilai rata-rata kelas kontrol ditunjukkan pada Gambar 1 dibawah ini

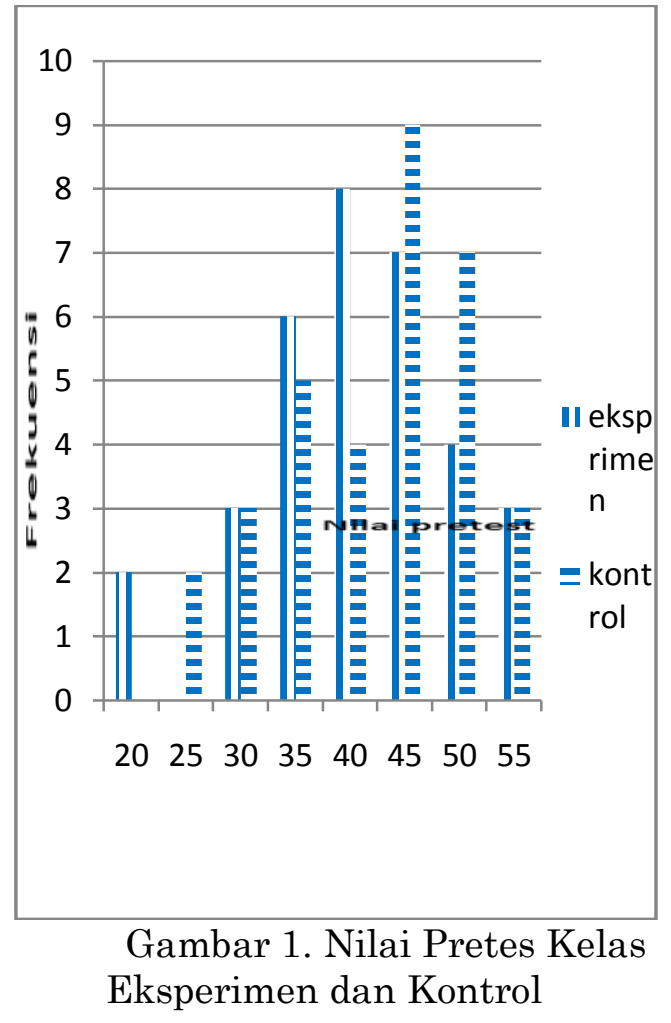

Setelah diberikan perlakuan yang berbeda dimana pada kelas eksperimen diberikan pembelajaran dengan model pembelajaran berbasis masalahdan pada kelas kontrol diberikan pembelajaran konvensional, diperoleh bahwa rata-rata postes kelas eksperimen sebesar 82,58 dan rata-rata postes kelas kontrol sebesar 71,21. Dari hasil ini tampak bahwa nilai postes kelas eksperimen lebihtinggi dibandingkan dengan kelas kontrol disimpulkan bahwa ada efek model pembelajaran berbasis masalahterhadap hasil belajar kognitif tinggi pada materi pokok suhu dan kalor di kelas $\mathrm{X}$ semester II SMA Swasta Al Hidayah Medan T.P 2014/2015.

Nilai rata-rata pretes kelas eksperimen dan nilai rata-rata kelas kontrol ditunjukkan pada Gambar 2 dibawah ini. 


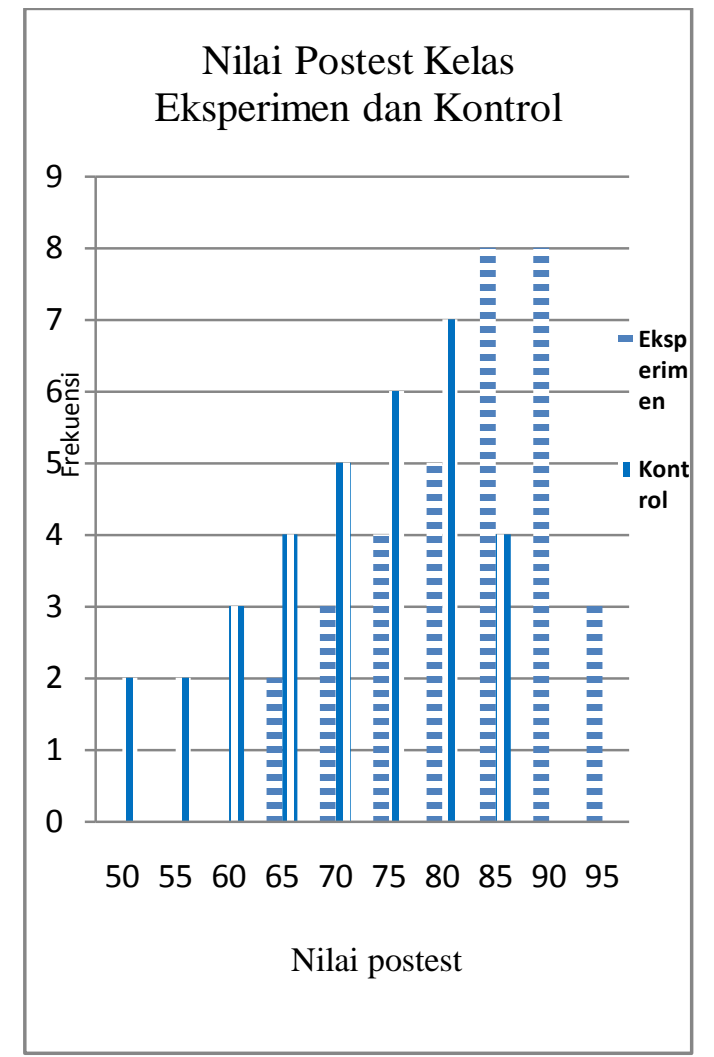

Gambar 2. Diagram batang datapostes kelas eksperimen dankelas kontrol

\section{Pembahasan}

Hasil penelitian menunjukkan bahwa pada kelas eksprimen yang diajar dengan menggunakan model pembelajaran berbasis masalah terjadi peningkatan hasil belajar, dimana nilai rata-rata pretestnya 40,60 sedangkan nilai rata-rata postest adalah 82,58. Peningkatan hasil belajar siswa di kelas eksperimen ini dikarenakan pada saat proses belajar mengajar dengan menggunakan model pembelajaran berbasis masalah menuntut siswa untuk bekerjasama dalam memecahkan masalah yang berkaitan dalam kehidupan sehari-hari dan menemukan sendiri informasi yang berkaitan dengan masalah. Sesuai dengan teori belajar konstruktivisme menyatakan bahwa siswa harus menemukan sendiri informasi yang kompleks, mengecek informasi baru dengan aturan-aturan lama dan merevisinya apabila aturanaturan itu tidak sesuai lagi. Bagi siswa, agar benar-benar memahami dan dapat menerapkan pengetahuan, mereka harus memecahkan masalah, menemukan segala sesuatu untuk dirinya, berusaha dengan susah payah dengan ide-ide. Maka dari itu, dalam proses pembelajaran siswa merasa sangat senang dengan adanya pembelajaran dengan mengunakan model pembelajaran berbasis masalah karena siswa bisa merasakan sendiri peristiwa yang berkaitan dengan kehidupan sehari-hari, yang sedang dipelajari.

Pada kelas kontrol yang diajar dengan menggunakan pembelajaran konvensional terjadi peningkatan hasil belajar,dimananilai rata-rata pretestnya 42,27 sedangkan nilai ratarata postest adalah 71,21. Besarnya peningkatan hasil belajar di kelas kontrol ini masih lebih rendah jika dibandingkan dengan kelas eksprimen yang menggunakan model pembelajaran berbasis masalah.

Hal ini disebabkan, pada pemebelajaran konvensional ini menyampaikan informasi dengan lisan kepada sejumlah siswa. Kegiatan ini berpusat pada penceramah dan komunikasi yang searah. Pada model pembelajaran konvensional, siswa belajar lebih banyak mendengarkan penjelasan di depan kelas dan melaksanakan tugas jika diberikan latihan soal-soal kepada siswa. Sistem konvensional pengajaran yang dilakukan dalam proses belajar mengajar yaitu dengan menggunakan metode ceramah, tanya jawab dan demonstrasi, sehingga siswa merasa bosan, pasif dan mudah cepat lupa.

Hasil penelitian menunjukkan bahwa rata-rata nilai postest di kelas eksprimen $(82,58)$ lebih tinggi daripada rata-rata nilai postest kelas kontrol (71,21). Sehingga dapat disimpulkan bahwa hasil belajar fisika menggunakan model pembelajaran berbasis masalah lebih baik daripada hasil belajar menggunakan konvensional. Hasil ini memberikan informasi bahwa ada efek yang positif model pembelajaran berbasis masalah 
dalam meningkatkan hasil belajar fisika siswa.

Adapun beberapa kelebihan dari model pembelajaran berbasis masalah adalah : 1. Meningkatkan motivasi belajar karena siswa dilibatkan secara aktif dalam proses pembelajaran, 2 . Siswa di latih untuk mengkaitkan permasalahan yang dipelajari dengan kehidupan sehari-hari sehingga siswa dituntut untuk belajar menemukan, 3 . Siswa lebih dalam berpikir tingkat tinggi, seperti menganalisis, memecahkan masalah yang terjadi dalam kehidupan sehari-hari, menemukan, mevaluasi, bekerja sama, menunjukkan komunikasi yang baik antar sesama teman .

Selain itu, model pembelajaran berbasis masalah dapat memberikan kesempatan pada siswa bereksplorasi mengumpulkan dan menganalisis data untuk memecahkan masalah, sehingga siswa mampu untuk berpikir kritis, analitis, sistematis, dan logis dalam menemukan alternatif pemecahan masalah. Siswa dalam hal ini aktif dan antusias untuk bekerja sama dengan teman satu kelompok dalam menyelesaikan masalah yang telah diberikan oleh peneliti. Siswa juga tertarik dan aktif saat berdiskusi dan mengeluarkan pendapat yang berbeda saat diadakan diskusi antar kelompok.

Pada tahap orientasi siswa pada masalah (pertama), peneliti memotivasi siswa dengan memberikan tujuan pembelajaran yang akan dicapai oleh siswa dan pada tahap ini peneliti memberikan masalah kepada siswa dengan menunjukkan dua buah alat percobaan yang berbeda. Pada tahap mengorganisasi siswa untuk belajar (kedua), peneliti memberikan materi pelajaran yang dipelajari kemudian membentuk kelompok-kelompok belajar dan melakukan percobaan (eksperimen). Pada tahap penyelidikan individual maupun kelompok (ketiga), peneliti membimbing setiap siswa untuk mengumpulkan informasi untuk memecahkan masalah, dan melakukan percobaan (eksperimen) sekali lagi. Pada tahap mengembangkan dan mempresentasikan artefak dan exhibit (keempat), peneliti membantu setiap kelompok menyelesaikan dan menjawab semua permasalahan yang ada, serta mempersentasikan hasil diskusi kelompok yang sudah disiapkan, kemudian kelompok yang lain diberikan kesempatan memberikan pendapat atau masukan. Pada tahap menganalisis dan mengevaluasi proses mengatasi masalah (kelima), peneliti membantu siswa dalam mengkaji ulang pemecahan masalah sesuai dengan tujuan pembelajaran dan memberikan penguatan pada pemecahan masalah tersebut dan pada tahap ini peneliti membuat tes evaluasi untuk mengetahui pemahaman siswa.

Hasil penelitian ini sejalan dengan penelitian terdahulu seperti yang di teliti oleh L.A.Kharida,dkk (2009), menyatakan dalam hasil penelitiannya terjadi peningkatan ratarata hasil belajar kognitif siswa yang diajar dengan model pembelajaran berbasis masalah. I Ketut Tika (2012), model PBL dapat meningkatkan secara signifikan pemahaman konsep fisika siswa. Orhan Akınoğlu and Ruhan Özkardeş Tandoğan (2010) showthatproblem-based active learning model had positively affected students' academic achievement and their attitudes towards the science course.

Sesuai dengan apa yang diakatan Arends (2011),"Model PBL ini tidak rumit,dan mudah untuk menangkap ide-ide dasar yang terkait dengan model ini.Akan tetapi,pelaksanaan efektif model ini lebih sulit.Sehingga,model ini membutuhkan banyak latihan dan mengharuskan untuk mengambil keputusan-keputusan tertentu selama perencanaan dan pelaksanaannya".

Walaupun model pembelajaran berbasis masalah telah membuat hasil belajar yang lebih baik dibandingkan dengan pembelajaran konvensional, tetapi ada beberapa hal kendala- 
kendala dalam melakukan penelitian yaitu: (1) Peneliti belum maksimal dalam mengelola waktu sehingga semua sintaks kurang efektif saat pelaksanaan proses pembelajaran. (2) Peneliti menemukan masalah dalam pengumpulan LKS karena kelompok lebih fokus pada penyelesaian masalah yang diberikan sedangkan LKS tidak bisa diselesaikan denggan tepat waktu.

\section{KESIMPULAN DAN SARAN Kesimpulan}

Berdasarkan hasil analisis uji statistik serta pembahasan maka disimpulkan bahwa pembelajaran secara konvensional sebelum diberikan perlakuan rata-rata pretes sebesar 42,27 dan setelah diberi perlakuan rata-rata postes siswa sebesar 71,21. Pembelajaran dengan model berbasis masalah sebelum diberikan perlakuan rata-rata pretes 40,60 Dan setelah diberi perlakuan rata-rata postes sebesar 82,58. Dari hasil uji hipotesis $t_{\text {thitung }}>t_{\text {tabel }}$ yaitu $4,91>1,999$, sehingga hasil belajar siswa dengan menerapkan model pembelajaran berbasis masalah memiliki efek yang lebih tinggi dibandingkan dengan pembelajaran konvensional.

\section{Saran}

Berdasarkan hasil penelitian dan kesimpulan di atas, maka sebagai tindak lanjut dari penelitian ini disarankan beberapa hal yaitu, Sebelum melakukan pembelajaran ini, terlebih dahulu mempersiapkan alat dan bahan tersendiri yang digunakan sebagai cadangan jika disekolah tidak memiliki alat dan bahan tersebut ataupun jika siswa tidak membawanya setelah anda memerintahkannya. Hendaknya menguasai semua sintaks dalam Pembelajaran Berbasis Masalah dan mengatur waktu untuk melaksanakan semua sintaks tersebut dengan tepat waktu dan siswa tersebut tidak merasa kesulitan di dalam mengikuti semua sintaks tersebut.

\section{DAFTAR PUSTAKA}

Akınoğlu, Orhan and Ruhan Özkardeş Tandoğan,(2007).The Effects of Problem Based Active Learning in Science Education on Students' Academic Achievement, Attitude and Concept Learning, Marmara Üniversitesi, Eurasia Journal of Mathematics, Eurasia Journal of Mathematics Science \& Technology Education 3.71-81.

Arends,Richard I,(2013), Learning to teach, Humanika Salemba,Yogyakarta.

Eko, P Candra. Eko,N Sunyoto. Wijayanto 2012. Penerapan Model Pembelajaran Guided Discovery Pada Materi Pemantulan Chaya Untuk Meningkatkan Berfikir Kritis. Unnes physics Edication Juornal.

Kharida,L.A,dkk, (2009), Penerapan Model Pembelajaran Berbasis Masalah Untuk Peningkatan Hasil Belajar Siswa Pada Pokok Bahasan Elastisitas Bahan, Jurnal Pendidikan Fisika Indonesia 5:8389.

Kuswana, W.S, (2012), Taksonomi Kognitif, PT Remaja Rosdakarya, Bandung.

Purwanto,(2011).Evaluasi Hasil Belajar, Pustaka Belajar, Yogyakarta.

Sudjana, N., (2005),Metoda Statistika, Tarsito, Bandung.

Tika, I Ketut,(2008).Penerapan Problem Based Learning Berorientasi Penilaian Kinerja Dalam Pembelajaran Fisika Untuk meningkatkan Kompetensi Kerja Ilmiah Siswa, Jurnal Pendidikan dan Pengajaran UNDIKSHA 3:648700 .

Trianto, (2009), Mendesain Model Pembelajaran Inovatif ${ }^{-}$ Progresif:Konsep, Landasan dan implementasinya pada Kurikulum Tingkat Satuan Pendidikan, Penerbit Kencana, Jakarta. 